\title{
Translation in Social and Environmental Sustainability: Case of Energy Sector in few Asian Countries
}

\author{
Md. Mahmudul Alam \\ (corresponding athor) \\ Institute for Environment and Development \\ National University of Malaysia \\ 43600, Bangi, Selangor, Malaysia \\ Email: rony000@gmail.com \\ Anurasiri Nalaka Geekiyanage Don \\ Department of Plant Sciences, \\ Faculty of Agriculture, \\ Rajarata University of Sri Lanka \\ Email: nalakagee@gmail.com \\ Aruna Prasad Nissanka Arachchillage \\ Southern Dryzone Development Programme \\ Care International \\ Kannattota, Sri Lanka \\ Email: narachchilage@co.care.org \\ Sacchidananda Mukherjee \\ National Institute of Public Finance and Policy \\ New Delhi, INDIA \\ E-mail: smukherjee@nipfp.org.in \\ Yuti Ariani Fatimah \\ School of Innovation Sciences \\ Eindhoven University of Technology \\ Email: Y.A.F.Padmadinata@tue.nl
}

\section{* Citation Reference:}

Alam, M.M, Nilaka, G.A., Nissanka, N.A., Mukherjee, S., \& Fatimah, Y.A. (2013). Translation in Social and Environmental Sustainability: Case of Energy Sector in Few Asian Countries, Policy Brief of UNU-IHDP, International Human Dimensions Programme (IHDP), UN University, Bonn, Germany.

This is a pre-publication copy.

The published POLICY BRIEF is copyrighted by

International Human Dimensions Programme (IHDP), UN University, Bonn, Germany

Project Reference Number: CBA2011-04NSY-IHDP

Project Link: https://www.apn-gcr.org/resources/items/show/1682 


\section{Translation in Social and Environmental Sustainability: Case of Energy Sector in few Asian Countries}

\section{Introduction}

In 1987, the Brundtland Commission introduced the term "sustainable development" to highlight the needs for taking the future generations into account. The term has evolved from only focusing on the human kind to reconciliation between humans and nature. On one hand, this evolution opens space for nature and vulnerable people to be acknowledged, on the other hand, it raises difficulties in implementing the idea due to its heterogeneity. By the mid 1990s, for instance, there were more than 100 definitions of sustainability (Marshall and Toffel, 2005). Rather than following previous scholars trying to find a general definition for sustainability, we try to approach it through the idea of translation. From this perspective, diversity is being bounded via others' right such as a practice is wrong whenever it might harm others and not because it looks different. Based on the argument above, we look at the energy sector within Asian countries in an attempt to increase variety in understanding sustainability.

\section{Energy Efficiency Experiences from Few Asian Countries}

Energy consumption is linked to the emission of greenhouse gases such as carbon dioxide, which has a detrimental impact on the global environment. Energy intensity, as measured by the primary energy consumption per dollar of gross domestic product (GDP) across a few selected countries in Asia is presented in Figure 1. It shows that energy intensity was higher for India and Pakistan as compared to other countries in this region until 1998. After 1998, the energy intensities of India and Pakistan show a falling trend. The energy intensity of Sri Lanka shows a different trend as compared to other countries, as it has been increasing since 1984 and hovering around 10,000 Btu/USD since 1989. The numbers for Thailand, Nepal and Bangladesh are quite different from those of other countries, too, as their energy intensity is constantly growing. In the case of Indonesia and Malaysia, energy intensity has grown until 2004 and after that shows declining trends. These trends might be caused by the rapid changes in these countries' economic structures. For example, the growing importance of the service sector for India's GDP is one of the reasons for falling energy intensity. The figure also shows that there is scope for the countries to adopt energy efficiency measures and illustrates where learning from each other's experience could be beneficial. 


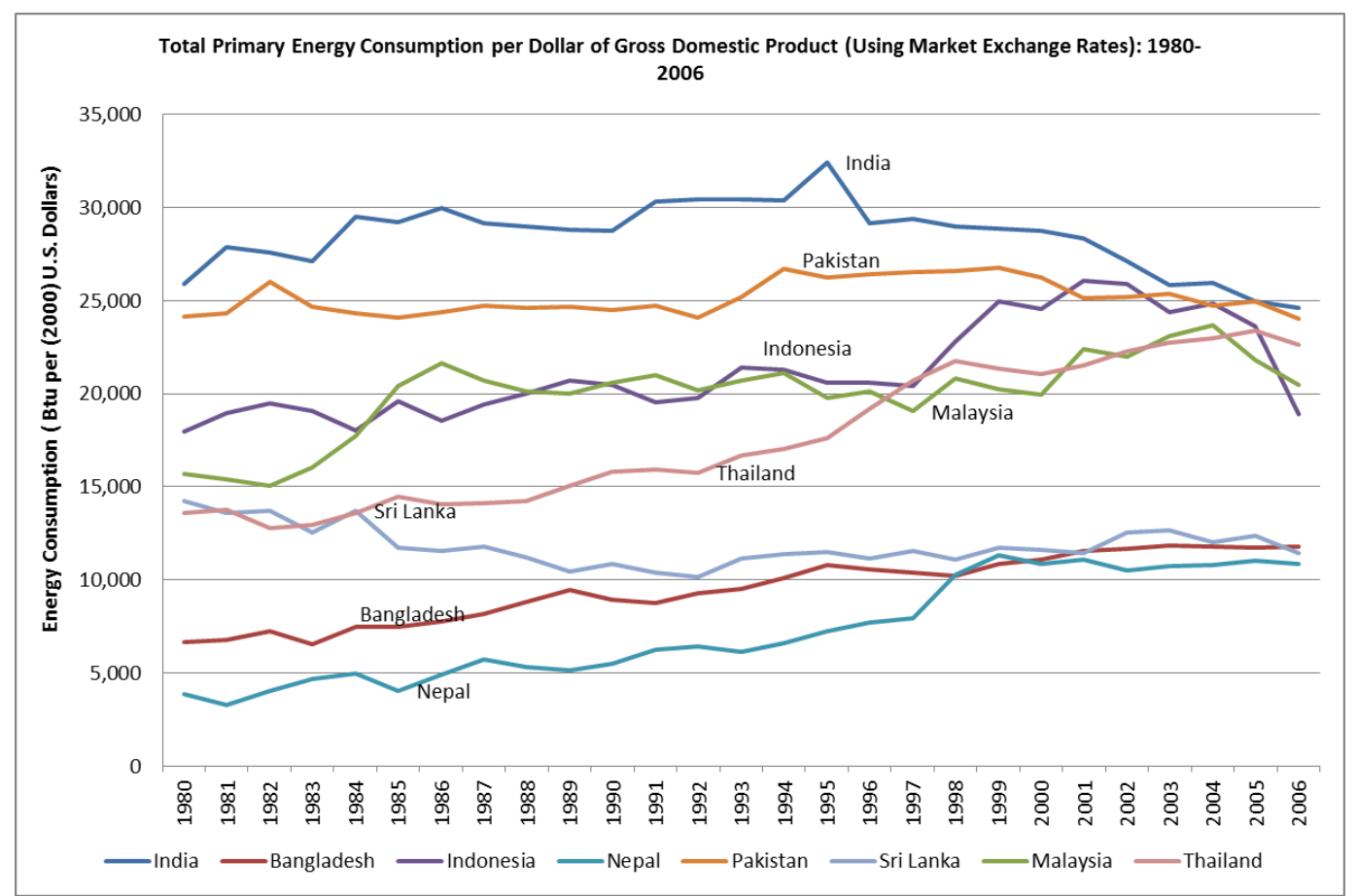

Figure 1: Energy Intensity across a few Selected Countries in Asia: 1980-2006 Data Source: International Energy Annual 2006

\section{Bangladesh}

After forty years of independence, Bangladesh still faces a serious energy crisis. Here, the term "energy crisis" is mainly referring to natural gas and electric power shortages. It is estimated that power outages result in an annual loss of industrial output worth $\$ 1$ billion. In 1971, 3\% of the total population in Bangladesh had access to electricity, while today approximately $40 \%$ of the population has access to electricity. The country can currently generate about 4500 megawatts (MW) at daytime and $5500 \mathrm{MW}$ during evening times, while the peak demand can be as high as $6500 \mathrm{MW}$. The annual growth rate of the demand for energy is $10 \%$. There was a proposal in the National Renewable Energy Policy of 2008 to upgrade grid technologies to digital smart metering systems and invest in renewable energy technologies to ensure they produce $5 \%$ of total power generation by 2015 and $10 \%$ by 2020 . With the desire to make electricity available to the whole population by 2021 , the government takes several policies in its Perspective Plan of Bangladesh 2010-2021, including (i) diversify the use of primary fuels, such as gas, coal and liquid fuel, for power generation; (ii) increase power generation through renewable sources, such as solar, wind, small hydro; (iii) finance power generation projects through, for example, public-private partnerships, government funding for Independent Power Producer (IPP); (iv) increase sector efficiency, and reform measures; (v) implement nuclear fuel based power plant, and looking for dual fuel in power plants.

Electricity Crisis in Bangladesh
Energy in Bangladesh is essential for almost all economic activities, ranging from
irrigation to the manufacturing of goods by small and micro enterprises and large
industries. Thus, it is also indispensible for achieving the Millennium Development
Goals (MDGs) as well as for the industrial growth of the country. Bangladesh still
allows natural gas to be used at homes for cooking on a flat rate and to run vehicles, but
there is not enough electric power supply on national grids. The per-capita energy


consumption in Bangladesh is one of the lowest $(136 \mathrm{kWH})$ in the world. Here, the coal mine is still in the development stage, and the natural gas reserves are expected to expire by 2020. Based on the current inefficient system, the corruption within the administration, the high system losses, the low plant efficiencies, the erratic power supply, the electricity theft, and the shortages of funds for power plant maintenance and new setup, it is highly questionable if achieving the target of electricity available to the whole population by 2021 is attainable.

\section{India}

Growing emphasis is given to diversify the basket of electricity generation by giving more importance to renewable and non-conventional sources of energy and promoting energy efficiency and energy conservation measures. By setting a specific target of achieving energy efficiency equivalent to the capacity of a $25,000 \mathrm{MW}$ power plant, India is following a leastcost option to meet the gap between demand and supply of electricity. Its government enacted the Energy Conservation Act 2010 to initiate energy efficiency drive in the country. The major energy efficiency measures prescribed in the act are as follows: (1) Standard and Labeling of Appliances; (2) Demand Side Management; (3) Energy Conservation Building Codes; (4) Strengthening Institutional Capacity of State Designated Agencies; (5) Establishment of Energy Conservation Fund; (6) Energy Efficiency in Small and Medium Enterprises (SMEs) and Designated Consumers; (7) Professional Certification and Accreditation; (8) Publication of Manual and Codes; (9) School Education Program; and (10) Energy Conservation Awards.

Bachat Lamp Yojana (BLY)
Bachat Lamp Yojana (BLY) promotes energy efficient and high quality compact
fluorescent lamps (CFLs) as a replacement for incandescent bulbs in households at the
rate of an incandescent bulb, i.e. Rs 15 . This would remove the barrier of high CFL
prices (currently Rs $80-100$ per CFL), which constrains its entry into households. BLY
targets the replacement of about 400 million incandescent bulbs in use in the country,
leading to a possible reduction of $4000 \mathrm{MW}$ of electricity demand, and a reduction of
about 24 million tons of $\mathrm{CO}_{2}$ emissions every year. The price difference would be
compensated by the project implementer through carbon credits earned, which could be
traded in the international market under Clean Development Mechanism (CDM) under
the UNFCCC Kyoto protocol.
Source: http://powermin.nic.in/JSP_SERVLETS/internal.jsp (last accessed on 23 July
2012)

\section{Indonesia}

After Indonesia became a net oil importer in 2004, the country changed its energy policy approach covering shifting: (i) priority from supply side management to demand side management; (ii) primary energy production from oil to oil and alternative energy; (iii) sectoral treatment from lex specialist to lex generalist; and (iv) subsidy reduction from pricing policy to substitution policy. These changes are being formalized through the Presidential Regulation of the Republic of Indonesia No. 5/2006 concerning national energy policy aimed to direct any efforts to implement the sufficiency of domestic energy supply. Its targets are (i) to achieve energy elasticity less than one in 2025, and (ii) to achieve optimal mix (primer) energy in 2025 by increasing variety in the energy consumption as follows: a) natural oil becomes less than $20 \%$; b) natural gas becomes more than $30 \%$; c) coal becomes 
more than 33\%; d) biofuel becomes more than 5\%; e) geothermal becomes more than 5\%; f) other energy sources such as biomass, nuclear, water power, solar heater, and wind power become more than 5\%; and $\mathrm{g}$ ) liquefied coal becomes more than $2 \%$.

\section{Complexity in Biofuel Settings}

In 2005, the Indonesian President increased the national oil price twice. Having oil subsidy since 1967, the decision triggered mass demonstrations and fractions within the Parliament whether to support the executive's decision or not. In response to the situation, the President held a closed meeting with his ministries and related actors, urging the need to launch a "Post-Crisis New Deal". The New Deal is built upon the argument that the current energy and financial crisis is partially caused by wrong approaches. In response to the situation, he suggested to focus on the agricultural sector and infrastructure, including a bio-energy action plan. The plan is being translated into a government-public-community partnership, a public-private funding scheme, and cooperation between regional government and state-owned enterprise. Those relationships aim to combine government intervention and market system. In practice, however, the two approaches create loss. The state oil company Pertamina, for instance, needs to make profit while at the same time it must follow the government's instruction to buy biofuel even though the production costs are higher as compared to fossil fuel. The company subsequently experienced losses amounting to 40 million US\$ between March 2006 and June 2008.

\section{Sri Lanka}

The National Energy Policy and Strategy is the main policy document in Sri Lanka identifying energy as a basic need for people to enhance their living standards (Ministry of Power and Energy, 2006). Furthermore, the document acknowledges the importance of maintaining the adequate and continuous supply of energy at the lowest cost to the economy to satisfy the increasing energy requirement of the population, arising from the country's economic development (Business As Usual scenario). The policy is applicable to electricity, petroleum products and biomass, which are the three main forms of energy used in Sri Lanka. Energy security is projected to be achieved through expanding the energy mix to secondary sources. The government promotes energy efficiency and conservation on both supply and demand sides. The main strategy is to shift from thermal energy to coal. Energy security in general is extremely vulnerable to climate change and the global oil crisis since the country depend on hydropower and imported petroleum to meet the energy demand.

\section{Smart Grid}

The Ministry of Power and Energy is introducing Smart Metering, which will encourage institutions from the private as well as the public sector to generate their own power and even sell the additional power generated back to the grid, using solar, wind, dendro and biomass. This project will be very beneficial to keep energy bills low and to earn an income through the generation of power. Prepaid meters will help consumers to control their energy bills. Other concepts such as net metering and feedin tariffs will also be introduced.

\section{Work of Translation}


Varieties in the cases above show different frames in understanding sustainability. The first frame presents the relationship between sustainability and energy in the Asian context. As an overall framework, the graph provides ideas on how different countries might contribute to environmental sustainability through energy efficiency. However, when we try to narrow the number to a specific case in an Asian country, it is clear that environmental sustainability has a strong correlation with other markets, as it is the case with CDM in India, MGD in Bangladesh, or with food in Indonesia. The idea of sustainability is thus moving within and through a frame; it needs a work of translation where each country or actor can adjust the idea of sustainability to their own context.

Stirling (2009) takes a similar approach when talking about plurality in innovation as a combination between (i) direction, highlighting common interest among various actors leading to an agreement such as in the Geneva Convention where two parties in a war has to protect the Red Cross that might safe their enemies; (ii) distribution, talking about the need of affirmative action where rich countries give aid to poor countries; and (iii) diversity, focusing on how the distribution is being adjusted to various voices. Those elements can be modeled into two stages as follows:

1. Contact zone: We adopt De Sousa Santos' ideas of a contact zone where commonalities are being constructed through constant struggles between various interests (De Sousa Santos, 2005:16). Each community or entity has the freedom to select things that they want to be put in the contact space, in which the sustainability of the whole community is determined. The denser the contact zone, the more sustainable it is, since its density represents the learning processed among different entities. Stirling's idea of direction and distribution is being performed in this stage, i.e. deciding what the common interest is, the need to protect actors, etc.

2. Point of Departure: After each community decides upon their contact zone, they should translate it into their local context. The idea of diversity works in this stage where each actor has to translate the abstract idea of sustainability into their daily life.

In translation, those elements work via the dynamics between two contrasts: convergence/diversity, order/chaos, and modulation/distribution. Law (2007) describes the friction between the two as follows: "Translation is about making (different things) equivalent, shifting, linking, and changing them" (p. 5). The cases above show that through the work of translation a normative concept can find its ground in practice.

\section{References}

De Sousa Santos, B. 2005. The Future of the World Social Forum: The work of Translation, Development 48(2): 15-22.

International Energy Annual. 2006. Total Primary Energy Consumption (Quadrillion Btu), All Countries, 1980-2006. U.S. Energy Information Administration. Available at <http://www.eia.gov/emeu/international/energyconsumption.html > Cited 30 May 2012

Law, J. 2007. Actor Network Theory and Material Semiotics.

Marshall, J.D., and Toffel, M.W. 2005.Framing the Elusive Concept of Sustainability: A Sustainability Hierarchy.Environmental \& Scientific Technology 39(3): 673-682.

Ministry of Power Energy. 2006. National Energy Policy and Strategies of Sri Lanka. Colombo, Ministry of Power and Energy: 1-19. 
Perspective Plan of Bangladesh 2010-2021. 2010. General Economics Division, Planning Commission, Government of The People's Republic of Bangladesh. Available at <http://planipolis.iiep.unesco.org/upload/Bangladesh/Bangladesh_Final_Draft_OPP Ju ne_2010.pdf $>$ Cited 30 May 2012

Renewable Energy Policy of Bangladesh. 2008. Power Division, Ministry of Power, Energy and Mineral Resources, Government of the People's Republic of Bangladesh. Available at <http://pv-expo.net/BD/Renewable_Energy_Policy.pdf > Cited 30 May 2012

Stirling, A. 2009. Direction, Distribution and Diversity! Pluralising Progress in Innovation, Sustainability and Development. Available at $<$ http://anewmanifesto.org/wpcontent/uploads/stirling-paper-32.pdf >Cited 24 Jun 2012 